\title{
Comparison of polycyclic aromatic hydrocarbons level between suspended solid and sediment samples of Pengkalan Chepa River, Kelantan state, Malaysia
}

\begin{abstract}
Sixteen type of common Polycyclic Aromatic Hydrocarbons (PAHs) which consist of naphthalene, acenaphthene, acenaphthylene, fluorene, phenanthrene, anthracene, fluoranthene, pyrene, benz[a]anthracene, chrysene, benzo[b]fluoranthene, benzo[k]fluoranthene, benzo[a]pyrene, benzo[ghi]-perylene, indeno[1,2,3-cd]-pyrene and dibenz[a,h]-anthracene in suspended solid and sediment samples of Pengkalan Chepa River, Kelantan state, Malaysia were investigated. The analysis samples were taken from six different sites of Pengkalan Chepa River during sunny day. The samples were subjected to a series of pre-treatment before the level of PAHs can be determined. A Gas Chromatographyï Mass Spectrometry (GCï MS) was the prime method for the analysis of PAHs level. A total of 16 PAHs concentration in suspended solid of the whole Pengkalan Chepa River was found to be $2144.6 \mathrm{ng} / \mathrm{g}$ dry weights. This concentration was about eight times more than 16 PAHs concentration in sediment which found to be $266.5 \mathrm{ng} / \mathrm{g}$ dry weights.
\end{abstract}

Keyword: PAHs; Pengkalan Chepa River; Sediment; Suspended solid 